\title{
Cloning and Expression of Leptospiral Immunoglobulin Like B Gene and Use of The Recombinant Antigen for The Diagnosis of Bovine and Caprine Leptospirosis
}

\author{
Yosef Deneke $^{1 *}$, Rajib Deb ${ }^{2}$ \\ ${ }^{1}$ School of Veterinary Medicine, Jimma University College of Agriculture and Veterinary Medicine, Jimma, \\ Ethiopia \\ ${ }^{2}$ ICAR-Central Institute for Resea on Cattle Indian Council of Agricultural Research, Grass Farm Road,
} Meerut-250 001, Uttar Pradesh, India

\section{Article Information}

Received: 06 May 2020

Revised version received: 12 June 2020

Accepted: 15 June 2020

Published: 25 June 2020

Cite this article as:

Y. Deneke and R. Deb (2020) Int. J. Appl. Sci. Biotechnol. Vol 8(2): 146-153. DOI: 10.3126/ijasbt.v8i2.29588

*Corresponding author

Yosef Deneke,

School of Veterinary Medicine, Jimma University College of Agriculture and Veterinary Medicine, Jimma, Ethiopia

Email: yosefdeneke@yahoo.com

Peer reviewed under authority of IJASBT

(C) 2020 International Journal of Applied Sciences and Biotechnology

\section{OPEN $A$ ACCESS}

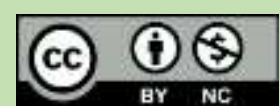

This is an open access article \& it is licensed under a Creative Commons Attribution Non-Commercial 4.0 International (https://creativecommons.org/licenses/by-nc/4.0/)

Keywords: Leptospirosis; LigB; MAT; rLigB based LAT

\begin{abstract}
In the present study recombinant $\operatorname{LigB}$ protein is employed in latex agglutination test, which is a cross reacting lipoprotein able to detect acute infection caused by any pathogenic leptospiral serovars. It was employed for serodiagnosis of leptospirosis. The 46KDa $6 \mathrm{X}$ His tagged LigB protein, obtained by IPTG induction of recombinant $E$. coli M15 cells containing the Nterminal region of $\mathrm{LigB}$ gee in $\mathrm{PQE30}$ expression vector, was purified by $\mathrm{Ni}$ NTA affinity chromatography and adsorbed on latex bead surface for performing latex agglutination test against Leptospirosis suspected field sea. Western blot confirmed that $\mathrm{rLigB}$ is an immunodominant protein against which antibodies are produced during active infection. A total of 453 field sera, including 432 bovine sera, 18 caprine sera and three sera samples of buffalo bull collected post-mortem following death the animal from Indian Veterinary Research institute (IVRI) were tested using $\mathrm{rLigB}$ based LAT. The result showed that 300 sera were tested positive by rLigB based LAT, which were reconfirmed using microscopic agglutination test (MAT). The results from LAT were in concordance with MAT. In conclusion, under laboratory and field conditions, rLigB based LAT is a rapid, pen site, reliable diagnostic tool of high sensitivity and specificity for the detection of Leptospirosis.
\end{abstract}

\section{Introduction}

Leptospirosis is considered as an important reemerging, ubiquitous Zoonotic disease worldwide, the incidence of which is uncertain and it is underestimated (Faine, 1982). In domestic animals, especially in dairy cattle. leptospirosis is an important cause of abortion, still birth, infertility, birth of weak calves, agalactia and death (Haake et al.,1998; Bhari et al., 2003; Theirmann, 1984; Murray, 1990; Cole, et al.,1973). In case of dogs the symptoms include fever, 
vomiting, dehydration, hepatitis, nephritis and death (Srivastava et al., 2006). In hoses, the important manifestations of leptospiral infection are abortion and uveitis (Palaniappan et al., 2002). In humans, leptospirosis is manifested as high fever, jaundice, nausea and vomiting, cephalgia, mayagia especially in lower limbs such as calf muscles, epistaxis, chest pain, dry coogh which later progress to Haemoptysis, haemorrhagic pneumonia, meningal involvement which leads to mental symptoms of delirium and hallucination, conjunctival suffusion, massive hemorrhages especially in gastrointestinal tract and adrenal glands and multiple organ failure mainly the liver and kidney ( Ferrat, 1990; Singh et al., 1999).

It is very difficult to diagnose leptospirosis in the early stage of the disease because; the initial symptoms are often indistinguishable from the other febrile illnesses. Anicteric leptospirosis is usually misdiagnosed as malaria, enteric fever, influenza or polynephritis. Icteric leptospirosis may be confused with viral hepatitis, septicemia with jaundice and malaria. For diagnostic purpose, the culture of leptospirosis from body fluids is the most demonstrative approach, but the technique can take up to two months and is very laborious. Even though, Dark Ground Microscopy (DGM) appears to be a simple and rapid procedure, the concentrations of the organisms present in the blood during acute stage the disease is too low to allow detection by direct microscopy. The leptospiral shedding in urine is intermittent. Moreover, serum proteins or cell fragments may mimic leptospires. Even experienced personnel may be confused with these artefacts (Vijayachari et al., 2001). Considering the problem in isolation or demonstration of leptospires in clinical samples, emphasis has been largely laid on serodiagnosis.

Microscopic Agglutination Test (MAT) has been the serological test of choice for the diagnosis of Leptospirosis and is also considered to be the gold standard test for detecting leptospirosis. The test is highly sensitive, serovar serogroup specific and performed on a paired-sera collected from acute and convalescent cases. MAT is therefore useful for epidemiological purpose since it gives clear idea regarding the circulating serovars in endemic regions. MAT shows and find out a sero-conversion or a four-fold rise in antibody titer, on sera collected during the acute and convalescent stage of the disease, which is the evidence of current or recent infection (Vijayachari et al., 2001). Since collection of convalescent serum sample is difficult in routine practice, several disease investigators usually consider a titer of 1 in 100 as a significant titer of diagnosis without considering the endemicity or baseline titers in the community.

However, MAT requires the use of several leptospiral serovars in their active growth phase whose maintenance is difficult, expensive, tedious and time consuming (Thiermann, 1983); Cousins et al., 1985; Bolin et al., 1989). The danger of acquiring the infection to laboratory technicians while handling the live leptospiral antigen, the cumbersome mechanism of recording the results and the need for paired sera samples to confirm the disease which delays disease diagnosis has made it difficult to adopt it as a routine lab test. Additionally, MAT can give false negative test result when the sera are collected from a patient in the early phases of the disease or when the patient is infected with a serovar which is not included in the Test. It has been reported that MAT gives also false positive test result, therefore low MAT titers need to be judged with some degree of caution since cross reactive antibodies in patients with syphilis, relapsing fever, Lymes disease, enteric fever, Dengue and malaria may give a titer of 1:80. MAT cannot distinguish between IgM antibodies indicative of current infection and $\mathrm{IgG}$ antibodies which are indicative of previous infection. Further MAT, is unable to differentiate between vaccinated and naturally infected animals' sera and give positive test result to both cases, which suggests that it is not used as DIVA based strategy.

Therefore, more widely acceptable approach of serodiagnosis like ELISA, LeptDipstck, Lepto-dri-dot, Lepto- lateral flow, Latex agglutination test have been developed, which take the advantage of using genus specific proteins present in the outer membrane of the pathogenic leptospiral organism (Guerriro, et al., 2001; Sehgal et al., 1999 and 2003; Vijayachari et al., 2002).

There are three classes of leptospiral outer membrane protins (OMPs) which have been identified a used for diagnostic purposes. The most abundant calss comprises the outer membrane lipoproteins which includes immunedominat protein antigen LipL32 (Haake et al., 2000), Lip L36, which is down regulated protein in vivo (Haake et al., 1998), LipL48 ( Haake and Matsungea, 2002), LipL41 which is surfaced exposed (Shang, et al.,1996) and bacterial immunoglobulin like domain proteins LigA and LigB (Matsunga et al., 2003).

The antigens which are well characterized for its diagnostic potential so far are LipL32 and LipL41 (Branger et al., 2001). Apart from these two lipoproteins, LigA and LigB proteins are drawing much attention. Anti-LigB IgM antibodies were found in sera of $92 \%$ of patients during the acute phase leptospirosis (Croda, et al., 2008). The research workers opined that the use of this markers may aid the prompt and timely diagnosis required to reduce the high mortality associated with severe form of the disease. Moreover, recent studies indicated the use of $\mathrm{N}$-terminal conserved region of LigB protein is useful for discriminating between naturally infected and vaccinated animals (Palaniappan et al., 2004). Therefore, the aims of the present study were-1) to standardize a diagnostic test like, latex agglutination test using recombinant LigB protein with sera samples collected from field 2) to comparatively determine the efficacy of rLigB latex agglutination test a microscopic agglutination test. 


\section{Materials and Method}

\section{Recombinant LigB protein expression and coating on latex beads}

In order to express the $\mathrm{N}$-terminal conserved region of $\operatorname{Lig} B$ gene a set of primers has been designed targeting a 1200bp long region of the $\operatorname{Lig} B$ gene. A polymerase chain reaction was performed to amplify the $1200 \mathrm{bp}$ long conserved Nterminal region of $\operatorname{Lig} B$ gene. The amplicon was extracted from gel according to manufacturer instruction. Using the PCR product as a template, a nested PCR was performed using a set of internal primers which gave rise to a product of $600 \mathrm{bp}$ by length. The $1200 \mathrm{bp}$ amplicon was then inserted in to TA cloning vector pTZ57R by using DNA ligase enzymes. This recombinant vector was used to transfer competent $E$. coli DH5 $\alpha$ cells treated with chilled $0.1 \mathrm{M}$ $\mathrm{CaCl}_{2}$ solution. Then, the recombinant cloned obtained were plated on Laura Bertani ampicillin plate to select the positive clones. In order to confirm the recombinants colony PCR and restriction digestion (RE) of the vector using SacI and HindIII enzymes were done. The insert released from pTZ57R vector was ligated to $\mathrm{pQE30}$ expression vector treated with the same set of RE enzymes and was transformed in to competent M15 cells of E. coli and the recombinant obtained were plated on $\mathrm{LB}$ ampicillin plates containing kanamycin. Then, colony PCR and RE digestion of the pQE30 vector using SacI and HindIII enzymes were also done for confirmation. The confirmed recombinant cells were used for expression of $\operatorname{LigB}$ gene by inducing the cells with $1 \mathrm{mM}$ Isopropyl B-D-1-thiogalactopyranoside (IPTG) during the log phase of growth and SDS-PAGE was then performed to check for the expression the recombinant protein. The leptospiral immunoglobulin like B protein appeared as a thick band at the expected size of $46 \mathrm{KDa}$. Later the minimum concentration required for the induction of LigB protein was determined to be $0.1 \mathrm{mM}$ IPTG. The time kinetics for the recombinant protein in SDS PAGE staring from two hours after induction and after eight hours maximum amount of LigB protein was detected in SDSPAGE. The production of the recombinant LigB protein in a large amount was achieved by inoculation a $0.5 \mathrm{ml}$ of bacterial culture in $100 \mathrm{ml}$ of LB broth containing ampicillin and kanamycin. The bacterial cells were harvested by centrifugation and the bacterial pellet obtained was dissolved in lysis buffer with a PH of 8.0 and kept in a rocking (horizontal shaker) platform for two hours. The lysis buffer containing lysed bacterial cells was then centrifuged at $10,000 \mathrm{rpm}$ for 20 minutes. The clear supernatant obtained was passed tough NI-NTA agarose chromatography column. The $6 \mathrm{X}$ histidine tagged $\mathrm{N}$ terminal portion of the LigB protein helps the protein to bind to Ni present in the chromatography column. The wash buffer at a PH of 6.3 was used to wash away any unbound protein. The bound LigB protein was eluted using elusion buffer at a $\mathrm{PH}$ of 4.5 . The presence of purified protein was then determined using SDS-PAGE and the fraction E3 - E6 $(0.5 \mathrm{ml}$ each) contained maximum concentration of the protein. A dialysis of these fractions against PBS was conducted to remove urea. The dialyzed protein was used to coat the latex beads were used which was used for performing latex agglutination test against field sera. These sensitized latex beads were stored at $4^{\circ} \mathrm{C}$ and used for performing LAT test against field sera suspected of Leptospirosis by detection of anti-LigB antibodies. Dot blot and western blot analysis were also done to test the immunoreactivity of LigB protein using a known positive and negative bovine sera samples.

\section{Screening of field sera samples suspected of leptospirosis by rLigB base LAT}

A total of 453 sera samples including 432 bovine sera and 18 caprine sera were tested using rLigB LAT.

Out of 432 bovine sera, 120 bovine sera samples suspected of Leptospirosis with a history of infertility, repeat breeding, abortion and retention of placenta were received from Mathura, Uttar Pradesh, 107 bovine sera samples were from suburban region of Kolkata, 102 bovine sera samples were from Pradip, Cuttack region (Odissa), 100 bovine sera were from $\mathrm{Kh}$, urda district Bhubaneswar region of Odissa and three sera samples of buffalo bull were collected after post-mortem following death the animal from Indian veterinary research institute( IVRI), India,. All the above fields sera samples were subjected to screening by rLigB based LAT as well as by microscopic agglutination test (MAT) utilizing 13 live leptospiral serovars and the result obtained with both tests were compared to check the sensitivity and specificity of the rLigB based LAT. For this purpose, $10 \mu \mathrm{l}$ of sera sample were placed on clean microscopic slide and $10 \mu \mathrm{l}$ latex beads sensitized with recombinant LigB antigen was mixed with the sera samples by gently rotating the slides and checked for agglutination.

\section{Results}

\section{Polymerase chain reaction amplification, rLig B protein expression and Dot-Blot ELISA/Western blot}

The result of PCR (1200 bp amplicon) confirming the Nterminal conserved region of $\operatorname{Lig} B$ gene and nested PCR (600 bp amplicon) for confirming the PCR product were shown in Fig. 1 and 2 respectively. The clones CL1, CL2, CL3, CL5, CL6 and CL8 expressed rLigB protein upon IPTG induction (Fig. 3). The minimum concentration required for the induction of LigB protein was determined to be $0.1 \mathrm{mM}$ IPTG (Fig. 4).The time kinetics for the recombinant LigB protein expression showed that detectable amount of recombinant protein was present in SDS PAGE starting from two hours after induction and after eight hours maximum amount of LigB protein was detected in SDS PAGE (Fig. 5). SDS PAGE of purified rLigB protein was showed in Fig. 6. The elution fractions E4-E6 $(0.5 \mathrm{ml}$ each) containing the maximum concentration of the 
protein obtained after purification of His-tagged LigB protein by Ni-NTA affinity chromatography is shown in Fig. 7. Dot blot of the bovine sera was shown in Fig. 8 and western blot of bovine sera Fig. 9. confirmed that recombinant LigB protein as an immunodominant protein against which antibodies are produced in the host during the active infection and anti LigB antibodies are present in sera of infected animals in higher concentration.

\section{L1}

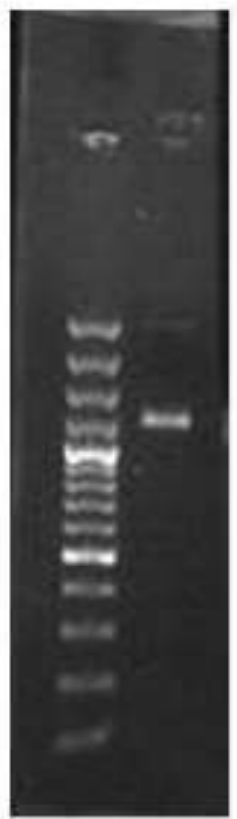

\section{$1200 \mathrm{bp}$}

Fig. 1: Agarose gel photograph of PCR amplification of Lig $B$ gene; M: Molecular marker 100bp; L1: Lig B gene amplicon (1200bp)

\section{L1}

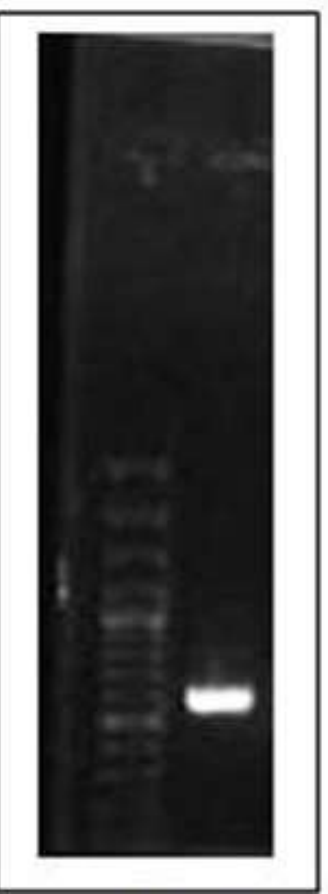

$600 \mathrm{bp}$

Fig 2: Nested PCR for confirmation of $\operatorname{Lig} B$ gene; $M$ : Marker; L1: Nested PCR product

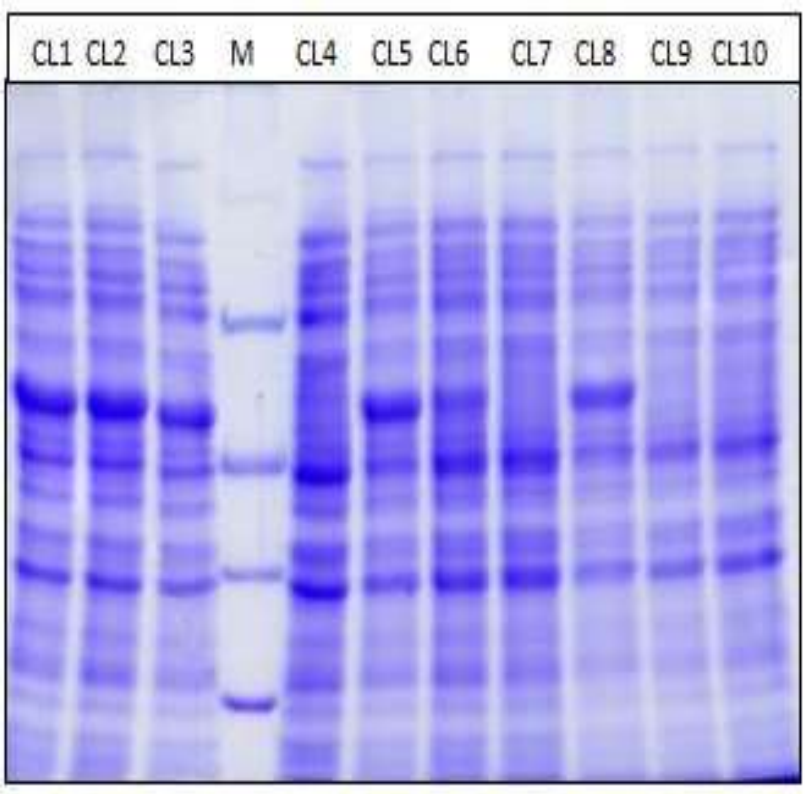

Fig.3: Clones Expressing rLigB; M: Marker; CL1-10: Clones $1-10$

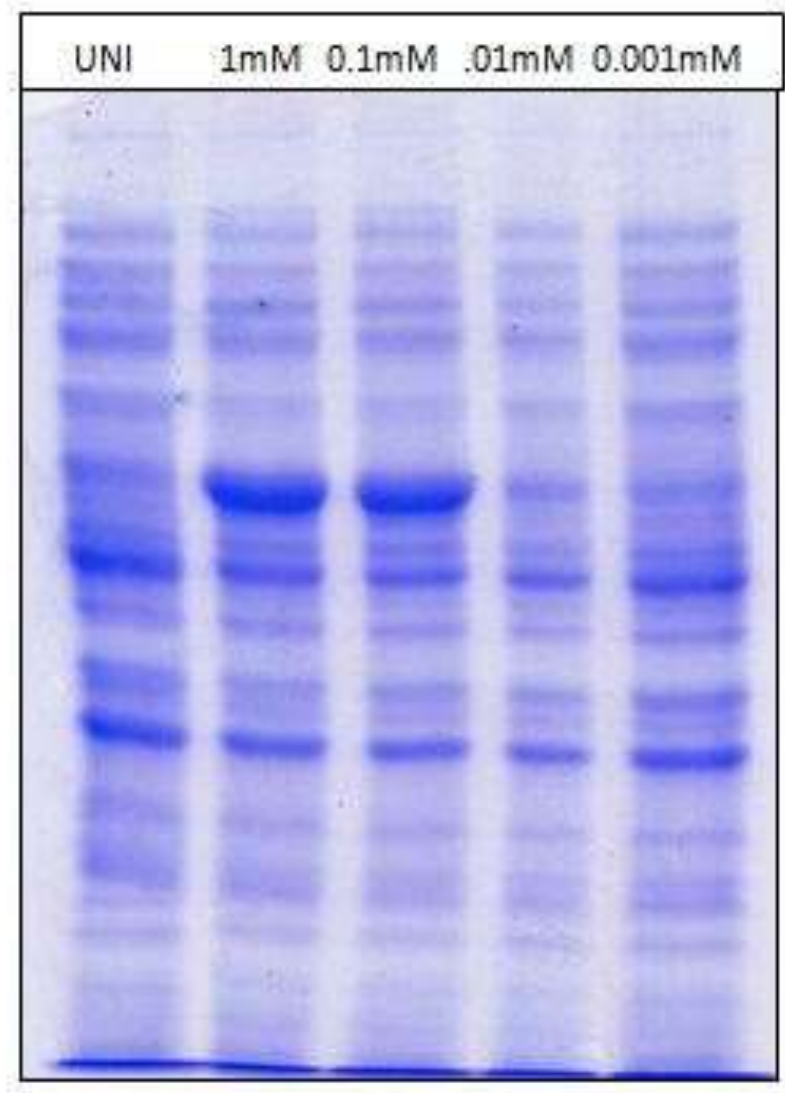

Fig 4: Expression kinetics showing minimum concentration of IPTG required for recombinant $\mathrm{LigB}$ protein induction UNI: Uninduced 


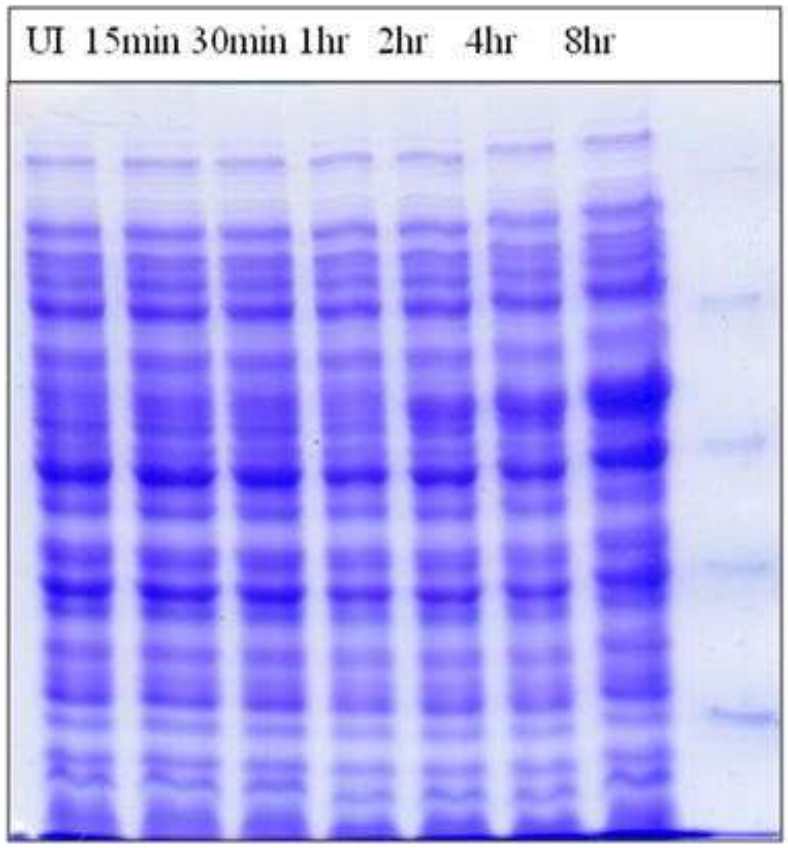

Fig.5. Expression kinetics of recombinant $\operatorname{Lig} B$ protein at various time intervals; UI: Uninduced

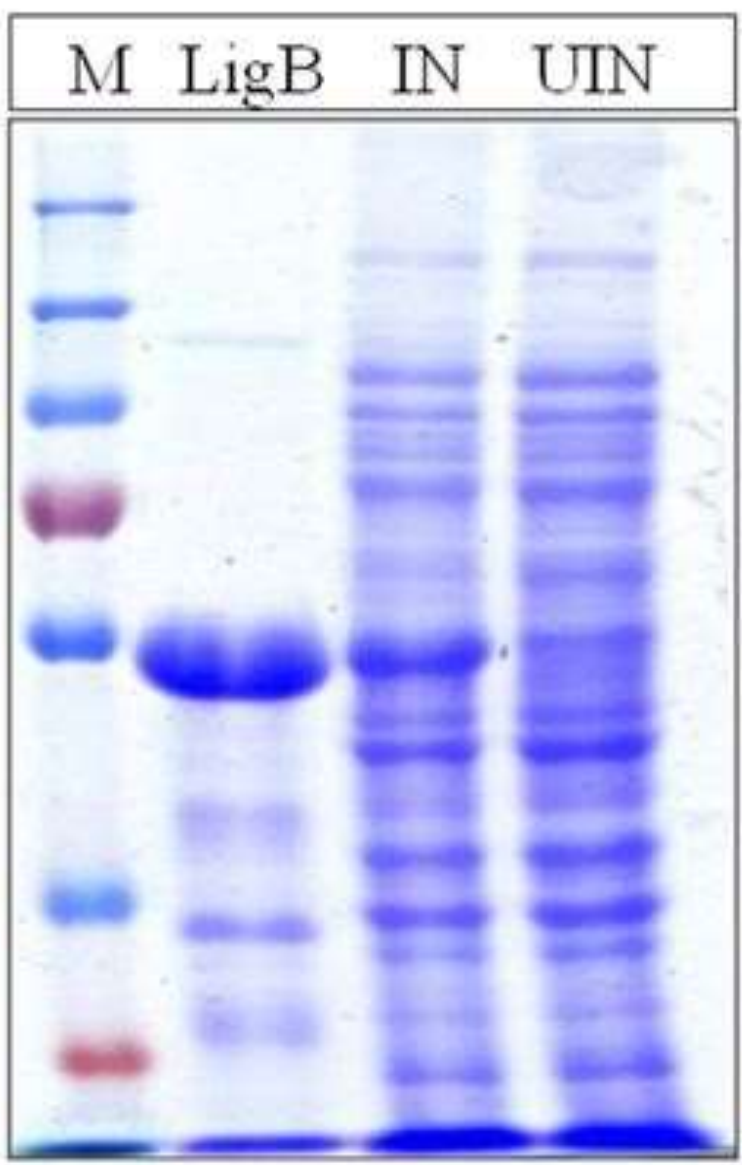

Fig. 6: SDS-PAGE showing lysate of uninduced and induced; M15 cells along with purified Lig B protein; M: Marker, $\operatorname{Lig} B$ protein, IN: Induced, UIN: Uninduced

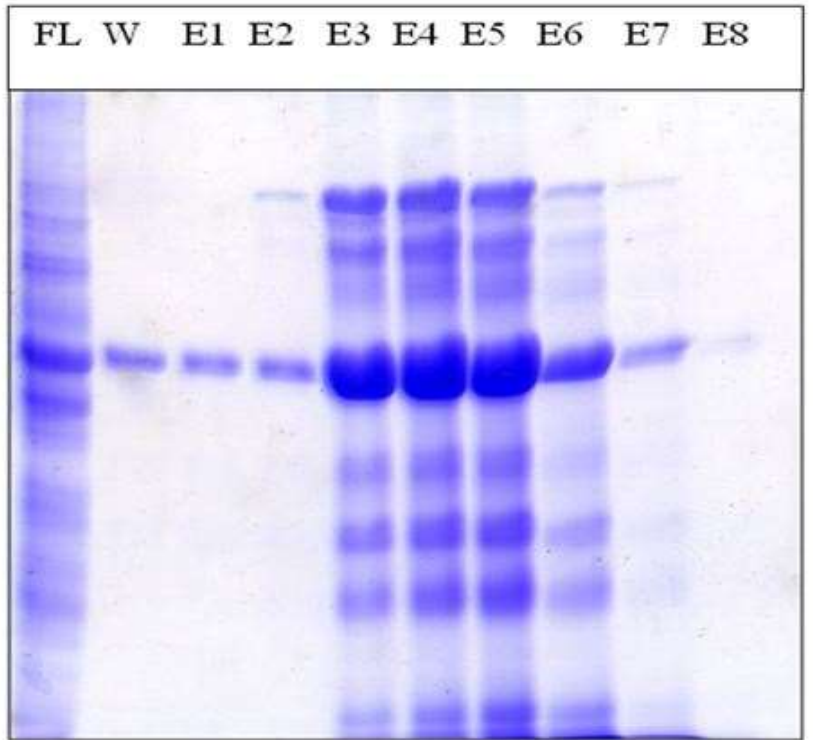

Fig. 7: SDS-PAGE showing purified recombinant $\operatorname{Lig} B$ protein in various elusion; Fractions; FL: Flow through, W: Wash, E1-E8: Elusion $1-8$.

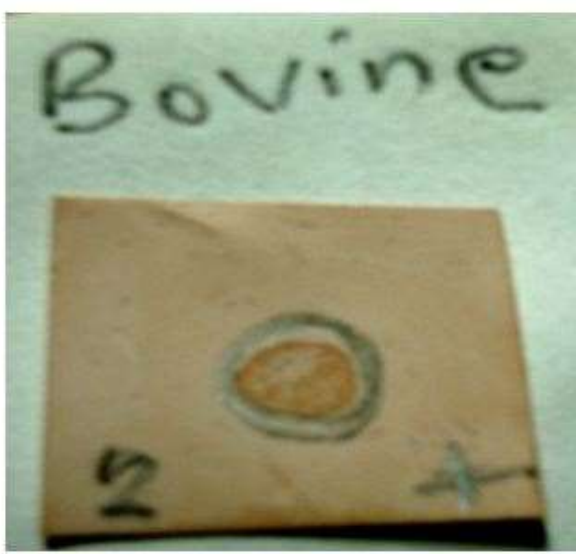

Fig. 8: Dot Blot of bovine sear using $\mathrm{r} L i g B$ protein

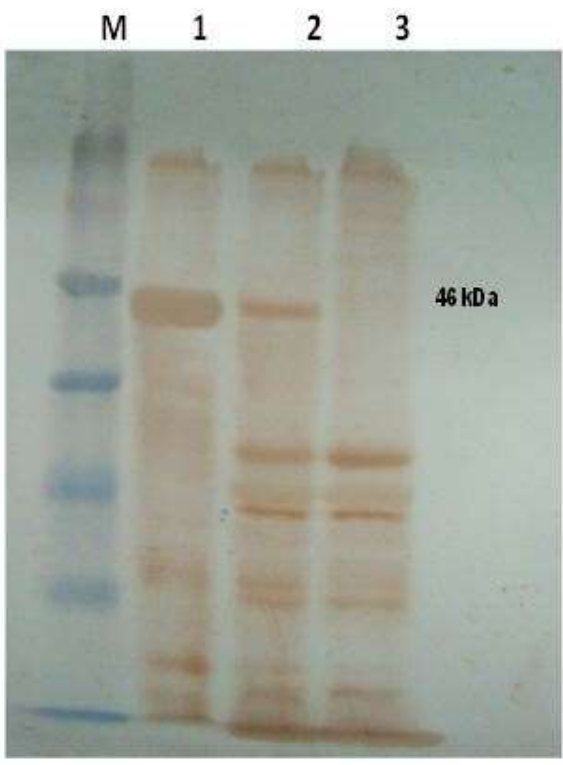

Fig. 9: Western blot Analysis of $\operatorname{Lig} B$ Protein using Bovine sera; M-protein Marker, Lane1-Purified LigB , Lane 2 - Induced M 15 cells, Lane 3- Uninduced M 15 cells 


\section{Recombinant LigB based latex agglutination test-based screening of field sera samples}

After coating the surface of the latex beads with recombinant LigB protein, field sera from leptospirosis suspected causes were screened by latex agglutination test. A total of 453 field sera of various animal species different part of the country suspected of the disease were screened in this manner.

Screening of bovine sera samples for Leptospirosis using LigB based latex agglutination test

From 120 bovine sera samples suspected for Leptospirosis with a history of infertility, repeat breeding, abortion and retention of placenta received from Mathura, Uttar Pradesh, were screened using rLig based LAT, a total of $90(75 \%$ seroprevalence) tested positive for the test (Fig. 10), It is reconfirmed using microscopic agglutination test. The test result obtained using LAT was in concordance with MAT. The serovar L. icterohaemorrgiae was the serovar against which majority of the serovar tested positive followed by $L$ grippotyphosa. The titer of most of the positive bovine sera ranged from 1:100 to 1:400 with six bovine sera showing seropositivity as high as 1:800.

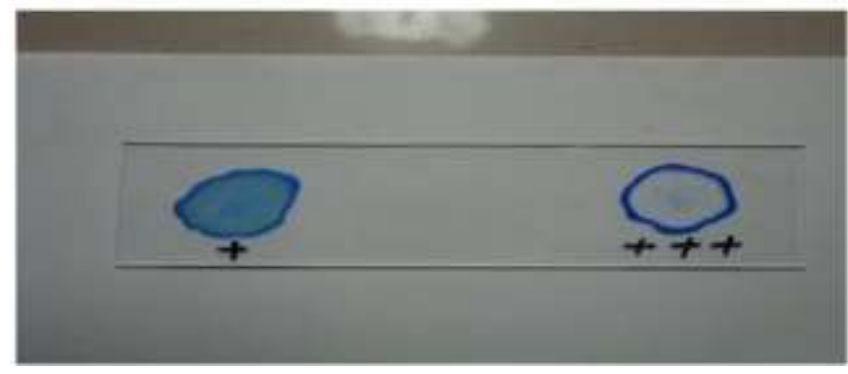

Fig. 10: Seroreactivity of rLigB based LAT with Bovine Sera; $\begin{array}{lll}\text { LAT test result } & + & +++ \\ \text { MAT test result } & 1: 100 & 1: 400\end{array}$

Seventy out of 107 bovine sera samples received from suburban region of Kolkata showed seropositivity for Leptospirosis with rLigB based LAT and testing by MAT revealed $L$. icterohaemorrahigae and L. grippotyphosa to be the most predominant serovars followed by $L$. hebdomadis and L. hardjo bovis. This high seroprevalence $(65 \%)$ recorded is may be attributed to the endemicity of the disease in the region.

Sixty three of the 102 bovine sera samples received from Paradip, Cuttack region of Odissa, India, showed seropositivity for Leptospirosis with rLigB LAT and tested later by MAT revealed that, $L$. hardjo bovis, $L$. hardjomadis, and L. icterohaemorrahigae to be the most prevalent serovars. This high prevalence of of $61.7 \%$ recorded is is may be attributed to the endemicity of the disease in the region.

Seventy two out of 100 bovine sera samples received from received from Khunda district, Bubaneshwar, were positive for Leptospirosis with rLigB LAT and the serovars, L. austarlis, L. grippotyphosa, and L. icterohaemorrahigae, were the predominant serovars.

Three sera samples of Buffalo collected post-mortem from CADRAD (IVRI) were tested for Leptospirosis and all the sera showed positive reaction both by LAT and MAT, where L. icterohaemorragiae was implicated in all three cases.

\section{Screening of caprine sera samples for Leptospirosis using rLigB LAT}

A total 18 sera samples, namely 10 sera samples obtained from Bihar of which only two were positive and all the 8 samples obtained from Jammu and Kashmir were positive by rLigB based LAT. The results reconfirmed using MAT showed concordance with the LAT results.

\section{Discussion}

As a simple, sensitive pen site diagnostic test latex agglutination test employing recombinant LigB protein would serve for rapid and reliable diagnosis of Leptospirosis under field conditions.

This diagnostic test would not require the use of highly skilled labour and the test results would be very easy to interpret. Thus LAT can be recommended for field studies in which speed and simplicity are crucial (Raboni, et .al. 2004). When the field sera is mixed with rLigB coated latex beads, anti-LigB antibodies present in the sera of animals naturally infected by leptospirosis interact with the antigen leading to the formation of fine and clearly visible granular agglutination.

The intensity of the agglutination depends on concentration of the antibodies in a sera sample. Clearly visible granular agglutination indicates the presence of specific antibodies to leptospires. In stronger reactions due to sera of high antibody titre, fine granular clumps tend to settle at the edge of the circle and the reaction time to form fine granular clumps is lesser than 60 seconds. Agglutination that occurs beyond 2-3 minutes may be due to evaporation and should be treated as doubtful cases When Latex beads are sensitised with $\mathrm{rLigB}$ protein which are cross reactive lipoproteins found on the outer membrane of most pathogenic leptospiral serovars, this test would be able to detect infection caused by any pathogenic leptospiral serovars. Unlike MAT which employs live whole Leptospiral antigens which pose danger to the lab technician performing the test, LAT employing rLigB protein is completely safe and non-hazardous. The coated latex particles are stable for long periods at $4^{\circ} \mathrm{C}$ and this long shelf life and cost effectiveness of this test makes this test a very desirable diagnostic tool for detecting leptospirosis. Other potential advantages of rLigB based LAT include its portability, limited amount of generated biomedical waste. The test find high level of application in developing countries such as India where it can be used in resource- 
poor settings, by investigators with only limited training. (Jackson, 2006)

The present study indicated that the sensitivity and specificity of recombinant LigB protein based latex agglutination test was comparable to microscopic agglutination test which is universally considered the gold standard test for diagnosis of leptospirosis. LaTeX agglutination test results were generally in concordance with MAT and it was also observed that a quantitative relation exists between both the tests. The field sera samples reacting strongly showed titer of 1:800 or above by MAT invariably gave $+++/++++$ test result with $\mathrm{rLigB}$ based LAT while weakly and moderately reactive field sera showed titer of 1:100 and 1:200 respectively by MAT gave + and ++ test result with $\mathrm{rLigB}$ based LAT

\section{Conclusion}

It can be concluded that, the rLigB based latex agglutination test having sensitivity and specificity comparable to microscopic agglutination test and also possessing the additional advantage of being to serve as a pen site diagnostic test, can be easily employed, in well-established Veterinary hospitals as well as in mobile veterinary clinics operating in remote, resource-poor settings,

\section{Author's Contribution}

Both of authors are equally contributed in all stages of research work, preparation of the manuscript and approval of the final form of the manuscript.

\section{Conflict of Interest}

The authors declare that there is no conflict of interest with present publication.

\section{Acknowledgement}

The author is thankful to the Ethiopian government for providing me the scholarship to study in India and also to the Director, IVRI, Izatnagar, for providing the facilities to carry out my research work.

\section{References}

Bhart AR, Nally JE, Ricald Matthias MA, Diaz M.M, Lovett MA, Levett PN, Gilman H,Willing MR, Gotuzzo E and Vinetz JM (2003) Leptospirosis: a zoonotic disease of global importance. The Lancet Infectious diseases 3(12): 757 771. DOI: $\underline{10.1016 / \text { S1473-3099(03)00830-2 }}$

Bolin CA, Zuerner RL and Trueba G (1989) Comparison of three techniques to detect Leptospira interrogans serovar hardjo type hardjobovis in bovine urine. Am J Vet Res 50: 1001-1003.

Bolin CA, Zuerner RL and Trueba G (1989) Comparison of three techniques to detect Leptospira interrogans serovar hardjo type hardjobovis in bovine urine. Am J Vet Res 50: 1001-1003.

Branger C, Sonrier C, Chatrenet B, Klonjkowski B, RuvoenClouet N, Aubert A, Andre' -Fontaine G. and Eloit M
(2001) Identification of the hemolysis- associated protein 1 as a cross-protective immunogen of Leptospira interrogans by adenovirus mediated vaccination. Infec Immun 69: 6831-6838. DOI: 10.1128/IAI.69.11.6831$\underline{6838.2001}$

Cole JR, Sulzer CR and Pursell AR (1973) Improved microtechnique for the leptospiral microscopic agglutination test. App. Micro. 25: 976-980. DOI: 10.1128/AEM.25.6.976-980.1973

Cousins DV, Robertson GM and Hustas L (1985) The use of the enzyme-linked immunosorbent assay (ELISA) to detect the IgM and IgG antibody response to Leptospira interrogans serovar hardjo, pomona and tarassovi in cattle Vet. Micro., 10: 439- 450. DOI: 10.1016/0378-1135(85)90026-4

Croda J, Matsunaga J, Queiroz A, Hamma A, Riley RW, Haake DA, Reis MG.and Ko AI (2007) Leptospira immunoglobulin -like proteins as a serodiagnostic marker foracute leptospirosis. J Clinic Micro 45: 1528- 1534. DOI: $\underline{10.1128 / \mathrm{JCM} .02344-06}$

Faine S. (1982) Guidelines for control of leptospirosis. Geneva, World Health Organization. Ferrar WE (1990) Leptospira species (leptospirosis): Principles and Practice of infectious diseases. In: Mandl G.L, douglas RG, Bennet JE (ed), Churchill Living stone. New York, 1813 - 1827.

Guerreiro H, Croda J, Flannery B, Mazel M, Matsunaga J, Galvao Reis M, Levett PN, Ko AI and Haake DA ( 2001) Leptospiral proteins recognized during the humoral immune response to leptospirosis inhumans. Infect and Immun 69: 4958-4968. DOI: 10.1128/IAI.69.8.4958$\underline{4968.2001}$

Haake DA and Matsunaga J (2002): Characterization of the leptospiral outer membrane and description of three novel leptospiral membrane proteins. Infect and Immun 70: 4936 - 4945. DOI: 10.1128/IAI.70.9.4936-4945.2002

Haake DA, Chao G, Zuerner RL, Barnett JK, Barnett D, Mazel M, Matsunaga J, Levett PN and Bolin CA (2000) The leptospiral major outer membrane Protein LipL32 is a lipoprotein expressed during mammalian infection Infect and Immun 68: 2276-2285. DOI: 10.1128/IAI.68.4.2276$\underline{2285.2000}$

Haake DA, Martinich C, Summers T A, Shang ES, Pruetz JD, McCoy AM, Mazel MK and Bolin CA (1998) Characterization of leptospiral outer membrane lipoprotein LipL36: down regulation associated with latelog- phase growth and mammalian infection. Infect and Immun 66: 1579- 1587. DOI: 10.1128/IAI.66.4.1579$\underline{1587.1998}$

Jackson CH, Glass MB, Ari MD, Bragg SL, Branch SL, Whittington CU, Edwards CN and Levett PN (2006) Evaluation of a commercial latex agglutination assay for the serological diagnosis of leptospirosis. J Clinic Micro 44: 1853 - 1855. DOI: $\underline{10.1128 / J C M .44 .5 .1853-}$ $\underline{1855.2006}$

Levett PN (2001). Leptospirosis. CliniMicro Rev 14: 296-326. DOI: 10.1128/CMR.14.2.296-326.2001 
Levett PN, Branch SL and Edwards CN (2000) Detection of dengue infection in patient investigated for leptospirosis in Barbados. American Journal of Trop Med and Hyg 62:112-114. DOI: 10.4269/ajtmh.2000.62.112

Matsunaga J, Barocchi MA. Croda J, Young TA, Sanchez Y, Siqueira I, Bolin CA, Reis MG, Riley LW, Haake DA and Ko AI (2003) Pathogenic Leptospira species express surface-exposed proteins belonging to the bacterial immunoglobulin super family. Molec Micro 49: 929-945. DOI: $\underline{10.1046 / \mathrm{j} .1365-2958.2003 .03619 . \mathrm{x}}$

Murray RD (1990) A field investigation of causes of abortion in dairy cattle. Vet Rec 127: 543-547.

Palaniappan RU, Chang YF, Jusuf SS, Artiushin S, TtimoneyJ.F, McDonough SP, Barr SC, Divers T.J, Simpson KW, McDonough PL and Mohammed HO (2002) Cloning and molecular characterization of an immunogenic LigA protein of Leptospira interrogans. Infect and Immun 70: 5924 - 5930. DOI: 10.1128/IAI.70.11.5924-5930.2002

Palaniappan RU, Chang YF, Hassan F, McDonough SP, Pough M, Barr SC, Simpson KW, Mohammed HO, Shin S, McDonough P, Zuerner RL and Qu JB (2004) Expression of leptospiral immunoglobulin-like protein by Leptospira nterrogans and evaluation of its diagnostic potential in a kinetic ELISA. J Med Micro 53: 975-984. DOI: 10.1099/jmm.0.45568-0

Raboni SM, Nogueira MB, Hakim VM, Torrecilha VTG, Lerner $\mathrm{H}$ and Tsuchiya LRV (2004) Comparison of Latex agglutination with enzyme immunoassay for detection of rotavirus in faecal specimens. Amer J of Clini Patho 117: 392-394. DOI: 10.1309/MUR1-05A4-184Q-QCTR

Sehgal SC, Vijayachari P, Sharma S and Sugunan AP (1999) LeptoDipstick - a rapid and simple method for serodiagnosis of leptospirosis in acute stage. Trans Roy Soc Trop Med Hyg 93:161-164. DOI: 10.1016/S00359203(99)90293-6
Sehgal SC, Vijayachari P, Sugunan AP and Umapathi T (2003) Field application of Lepto-lateral flow for rapid diagnosis of leptospirosis. J Med Micro 52: 1- 6. DOI: 10.1099/jmm.0.05064-0

Shang ES, Summers TA and Haake DA (1996) Molecular cloning and sequence analysis of the gene encoding LipL41, a surface-exposed lipoprotein of pathogenic Leptospira species. Infect Immun 64: 2322-2330. DOI: $\underline{\text { 10.1128/IAI.64.6.2322-2330.1996 }}$

Sharma S, Vijayachari P, Sugunan AP and Sehgal SC (2003) Leptospiral carrier state and seroprevalence among animal population a cross sectional sample survey in Andaman \& Nicobar Islands. Epidemiology and Infection 131: 985989. DOI: $10.1017 / \mathrm{S} 095026880300880 \mathrm{X}$

Singh SS, Vijayachari P, Sinah, A, Sugunan AP, Rashid MA and Shegal S C (1999) Clinico-epidemiological study of hospitalized cases severe leptospirosis. In J Med Res 189: $94-99$.

Srivastava SK (2006) Prospects of developing leptospiral vaccines for animals. Indian J Med Micro 24: 331-336. DOI: 10.4103/0255-0857.29412

Thiermann AB (1983) Bovine leptospirosis: Bacteriologic versus serologic diagnosis of cows at slaughter. Am J Vet Res 44: 2244- 2245.

Vijayachari P, Sugunan AP and Sehgal SC (2002) Evaluation of Lepto dri-dot as a rapid test for the diagnosis of leptospirosis. Epidemiology \& Infection 129(3): 617-621. DOI: $\underline{10.1017 / \text { S0950268802007537 }}$

Vijayachari P, Sugunan AP and Sehgal SC. (2001) Role of Microscopic Agglutination Test (MAT) as a diagnostic tool during acute stage of leptospirosis in low and high endemic areas. In J Med Res 114: 99-106 